\title{
EKSTRAKSI DAN OPTIMASI VITAMIN E DARI FRAKSI NON POLAR CRUDE PALM OIL (CPO)
}

\author{
Rahmiwati Hilma1, Anggi Fisi Anggita', Ihsan Ikhtiarudin ${ }^{2}$ \\ ${ }^{1}$ Program Studi Kimia, Universitas Muhammadiyah Riau. \\ ${ }^{2}$ Sekolah Tinggi Ilmu Farmasi Riau \\ email : rahmiwatihilma@umri.ac.id
}

\begin{abstract}
Vitamin E has many benefits for human health. Besides being known as supplements, vitamin $E$ is known to have activities as an anticancer compound, preventing premature aging, preventing cardiovascular diseases and other degenerative diseases. In this study carried out the extraction and optimization process of vitamin E from sample non-polar fraction of fresh CPO. The extraction process was carried out by saponification reaction, vitamin E optimization was carried out on the non-polar fraction with the addition of methanol, then to the oil fraction added 2-propanol (1\%) in hexane. From the fresh CPO samples used, it was seen that the samples met the quality standards of fresh CPO. From the results of extraction and optimization of vitamin $E$, it was found that the yield was quite large (52.77\%). Characterization results with TLC and analyzed with UV light at a wavelength of 254 and $366 \mathrm{~nm}$ seen vitamin E still has 2 stains, the possibility was tocopherol and tootrienol which was usually components contained in vitamin $E$.
\end{abstract}

Key words : Crude Palm Oil (CPO), extraction, optimation, vitamin E

\begin{abstract}
Abstrak
Vitamin E memiliki banyak manfaat bagi kesehatan manusia. Selain yang dikenal sebagai suplemen, vitamin E diketahui mempunyai aktivitas sebagai senyawa antikanker, mencegah penuaan dini, mencegah penyakit kardiovaskuler dan penyakit degeneratif lainnya. Pada penelitian ini dilakukan dilakukan proses ekstraksi dan optimasi vitamin E fraksi non polar sampel CPO segar. Proses ekstraksi dilakukan dengan reaksi saponifikasi, optimasi vitamin E dilakukan terhadap fraksi non polar dengan penambahan metanol, selanjutnya terhadap fraksi minyak ditambahkan 2-propanol (1\%) dalam heksana. Dari sampel CPO segar yang digunakan terlihat bahwa sampel memenuhi baku mutu CPO segar. Dari hasil ekstraksi dan optimasi vitamin E didapatkan rendemen yang cukup besar (52,77\%). Hasil karakterisasi dengan KLT dan dianalisa dengan lampu UV pada panjang gelombang 254 dan $366 \mathrm{~nm}$ terlihat vitamin $\mathrm{E}$ masih mempunyai 2 noda, kemungkinanannya adalah tokoferol dan tokotrienol yang biasanya menjadi komponen yang terdapat didalam vitamin $\mathrm{E}$.
\end{abstract}

Kata kuci : Crude Palm Oil (CPO), ekstraksi, optimasi, vitamin E

\section{PENDAHULUAN}

Vitamin E termasuk dalam vitamin yang larut dalam lemak dan mempunyai aktivitas menghambat pembentukan radikal bebas atau yang lebih dikenal sebagai antioksidan. Vitamin E terbagi menjadi beberapa isomer, yaitu struktur $\alpha$ tokoferol, $\beta$ - tokoferol, $\gamma$ - tokoferol, $\delta$ tokoferol, dan tokotrienol (Śebayang et al., 2016). Tokoferol merupakan salah satu 
antioksidan fenol alami yang paling banyak ditemukan dalam minyak nabati (Amelia, et al., 2014). Tokoferol mempunyai keaktifan vitamin $\mathrm{E}$ dan mempunyai banyak ikatan rangkap yang mudah dioksidasi sehingga akan melindungi lemak dari oksidasi (Arpi, 2014). Vitamin E memiliki banyak manfaat bagi kesehatan manusia. Selain yang dikenal sebagai suplemen, vitamin $\mathrm{E}$ diketahui mempunyai aktivitas sebagai senyawa antikanker, mencegah penuaan dini, mencegah penyakit kardiovaskuler dan penyakit degeneratif lainnya (Kresnawaty et al., 2012).

Minyak sawit atau Crude Palm oil (CPO) memiliki potensi besar untuk dikembangkan menjadi produk farmaseutikal dan nutraseutikal, di antaranya karena kandungan tokoferol (Sinaga et al., 2015). Kandungan vitamin E yang terdapat pada kelapa sawit didominasi oleh tokoferol. Jenis tokoferol lainnya diantaranya tokotrienol pada kelapa sawit lebih tinggi dibandingkan dengan sumber lain, seperti, minyak kacang, padi, barley, gandum, jagung, kapuk, bunga matahari, dan kacangkacangan. Tokoferol di dalam minyak sawit berkisar antara 600-1.000 ppm, bahkan pada residu minyak serabut sawit

\section{METODOLOGI PENELITIAN}

\section{Alat dan bahan yang digunakan}

Alat yang digunakan dalam penelitian ini yaitu spektrofotometerUVVis, neraca analitik, alat-alat gelas yang biasa diapakai di Laboratorium.

Bahan yang digunakan dalam penelitian ini adalah Crude Palm Oil (CPO) yang diperoleh dari PT. Minamas Plantation, $n$-heksana, $\mathrm{NaOH}, \quad B u t i l$ Hidroksi Toluena (BHT), $\mathrm{NaCl}$, etanol, aquades, silika gel, zeolit,Tetrahidrofuran kandungan tokoferol mencapai 2.0004.000 ppm (Kresnawaty et al., 2012).

Berbagai cara dikembangkan untuk mendapatkan tokoferol dari minyak sawit, tetapi kompleksitas dan variasi struktur yang luas, menyebabkan perlunya teknik isolasi, diferensiasi dan kuantifikasi masing-masing komponen dari campuran yang diperoleh dari suatu sampel. Ekstraksi umum yang digunakan adalah dengan menggunakan saponifikasi alkali dan ekstraksi fraksi yang tidak tersaponifikasi dengan dietil eter yang diikuti oleh analisis penentuan tokoferol (Sinaga et al., 2015).

Penelitian sebelumnya oleh Andulaa et al., (2017) melaporkan studi perbandingan analisis vitamin $\mathrm{E}$ minyak sawit merah tersafonifikasi antara metode spektrofotometri UV Visdan HPLC. Pada penelitian tersebut, vitamin $\mathrm{E}$ yang diperoleh hanya berupa fraksi hasil ekstraksi saponifikasi minyak sawit merah. Oleh karena itu, pada penelitian ini, penulis tertarik untuk mengisolasi vitamin E dari CPO yang diproduksi oleh PT. Minamas dengan metode ekstraksi dan optimasi saponifikasi vitamin E untuk mendapatkan vitamin $\mathrm{E}$ denagn rendemen yang lebih banyak.

(THF), petrolium benzen, dietil eter, asam asetat, dan 2-propanol, larutan wijs, etanol, kloroform, $\mathrm{KI}, \mathrm{Na}_{2} \mathrm{~S}_{2} \mathrm{O}_{3}, \mathrm{HCl}$, indikator pp, asam asetat, larutan amilum dan aquadest.

\section{Prosedur Penelitian}

\section{Preparasi CPO (SNI 7709:2012)}

CPO didapatkan dari pabrik pengolahan minyak kelapa sawit PT. Minamas di Kabupaten Siak, Propinsi Riau. Kemudian CPO di bawa ke Laboratorium Kimia Universitas 
Muhammadiyah Riau. Di Laboratorium CPO langsung dimasukkan ke dalam freezer agar awet dan tidak rusak.

\section{Pengujian Mutu Sampel CPO yang akan digunakan}

Pengujian mutu CPO meliputi Uji Asam Lemak Bebas (ALB), Uji Peroksida dan Uji Bilangan Iod mengikuti SNI 7709:2012

\section{Reaksi Saponifikasi (Modifikasi metode Andula et al.,2017)}

$20 \mathrm{~g}$ sampel dimasukkan ke dalam erlemenyer $250 \mathrm{~mL}$ dan ditambahkan 20 $\mathrm{mL}$ etanol 96\%, $60 \mathrm{~mL} \mathrm{NaOH} \mathrm{0,25} \mathrm{M} \mathrm{dan}$ $50 \mathrm{~mL}$ BHT 0,3 M. Kemudian ditempatkan dalam penangas air pada temperatur $70^{\circ} \mathrm{C}$ selama 45 menit dan dikocok setiap 5-10 menit selama proses saponifikasi. Setelah itu didinginkan dalam penangas es dan ditambahkan $\mathrm{NaCl}$ 0,02 M sebanyak $100 \mathrm{~mL}$. Dimasukkannya kedalam corong pisah dan dibiarkan hingga terbentuk tiga lapisan. Bagian atas adalah fraksi minyak yang tak tersabunkan, bagian tengah adalah fraksi minyak yang tersabunkan dan bagian bawah adalah fraksi air. Hasil reaksi saponifikasi dilakukan optimasi ekstraksi vitamin $\mathrm{E}$ dengan cara dipisahkan fraksi yang tak tersabunkan atau fraksi non polar, lalu ditambahkan dengan $70 \mathrm{~mL}$ metanol, dan didiamkan hingga terbentuk menjadi dua fraksi. Fraksi bagian atas diambil dan ditambahkan dengan $20 \mathrm{~mL}$ 2-propanol (1\%) dalam heksana.

Fraksi non polar atau yang larut nheksan (bagian atas) diuapkan pelarutnya dan dikarakterisasi dengan KLT dan lampu UV.

\section{HASIL DAN PEMBAHASAN}

Hasil Nimai Mutu Sampel CPO Segar Yang Digunakan

Pada penelitian ini dilakukan isolasi $\alpha$-tokoferol dari CPO dengan menggunakan metode saponifikasi yang dilanjutkan optimasi vitamin E. Metode saponifikasi terdiri dari beberapa tahap antara lain saponifikasi CPO, ekstraksi dan optimasi vitamin E. Selanjutnya vitamin E hasil ekstraksi dan optimasi di karakterisasi dengan KLT dan lampu UV.

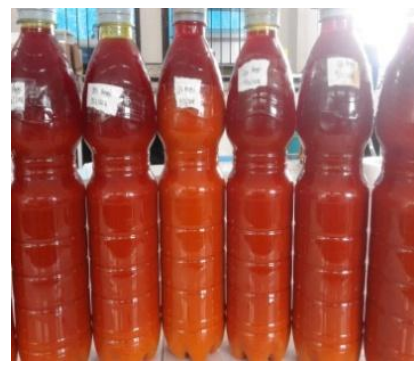

Gambar 1. Sampel CPO segar yang digunakan

Hasil uji mutu sampel awal CPO meliputi: kadar asam lemak bebas, kadar peroksida dan bilangan Iod harus memenuhi baku mutu standar CPO segar. Kadar FFA < 3,5 \% (SNI -01-2901-2006), Standar BP maks $10 \mathrm{Meq} / \mathrm{kg}$ (SNI 37412013)dan Standar Bilangan Iod : 50-55 (SNI -01-2901-2006). Dari hasil pengujian mutu terlihat bahwa sampel CPO yang digunakan memenuhi baku mutu CPO segar dan sanagt layak untuk dijadikan sampel penelitian.

\section{Hasil Uji Asam Lemak Bebas}

Hasil uji asam lemak bebas menggunakan metode titrimetri pada sampel CPO yang digunakan, didapatkan hasil seperti pada tabel 1 . 
Tabel 1. Hasil Uji nilai asam lemak bebas CPO

\begin{tabular}{cccc}
\hline Paramater & \multicolumn{3}{c}{ Asam Lemak Bebas } \\
\cline { 2 - 4 } & Ulangan 1 & Ulangan 2 & \%RPD \\
ALB & 1.8772 & 1.7064 & 6.2555 \\
\hline
\end{tabular}

*Standar ALB <3.5\% (SNI -01-2901-2006)

$* \%$ RPD $: \leq 10 \%$

\section{Kadar Peroksida}

Hasil uji kadar peroksida menggunakan metode AOAC 1995 pada sampel CPO yang digunakan.

Tabel 4. Rata-rata bilangan peroksida pada CPO

\begin{tabular}{cccc|}
\hline \multirow{2}{*}{ Paramater } & \multicolumn{3}{c|}{ Antioksidan (g/ 250 mL CPO) } \\
\cline { 2 - 4 } & Ulangan 1 & Ulangan 2 & \%RPD \\
\hline BP H-0 & 0.4414 a & 0.4415 & 0.0151
\end{tabular}

*Standar BP maks 10 Meq/kg (SNI 3741-2013)

$* \%$ RPD : $\leq 10 \%$

\section{Bilangan Iod (BI) Pada CPO}

Hasil uji kadar bilangan iod menggunakan metode AOAC 1995 pada

Tabel 4. Rata-rata bilangan iod pada CPO

\begin{tabular}{cccc}
\hline \multirow{2}{*}{ Paramater } & \multicolumn{3}{c}{ Antioksidan (g/ 250 mL CPO) } \\
\cline { 2 - 4 } & Ulangan 1 & Ulangan 2 & \%RPD \\
\hline BIH-0 & 52.4946 & 53.0654 & 0.7223
\end{tabular}

*Standar BI : 50-55 (SNI -01-2901-2006)

* \%RPD : $\leq 10 \%$

\section{Ekstraksi Saponifikasi vitamin E dari} CPO

Saponifikasi dilakukan untuk memisahkan komponen minyak dan vitamin E yang dapat mempengaruhi Vitamin E. Komponen minyak akan tersaponifikasi karena adanya reaksi basa kuat dengan asam lemak. Fungsi penambahan BHT pada reaksi saponifikasi yaitu sebagai antioksidan yang berperan untuk mencegah reaksi oksidasi vitamin $\mathrm{E}$ sampel CPO yang digunakan, didapatkan hasil seperti pada tabel 4 . yang sudah terpisah dari lemak (Kresnawaty et al., 2012). Saponifikasi dilakukan pada suhu $70^{\circ} \mathrm{C}$ agar mempercepat reaksi, suhu yang lebih tinggi dan waktu yang relatif lama akan merusak isomer vitamin $\mathrm{E}$, sedangkan waktu yang lebih singkat menyebabkan penurunan tingkat regenerasi isomer (Andulaa dkk, 2017). 

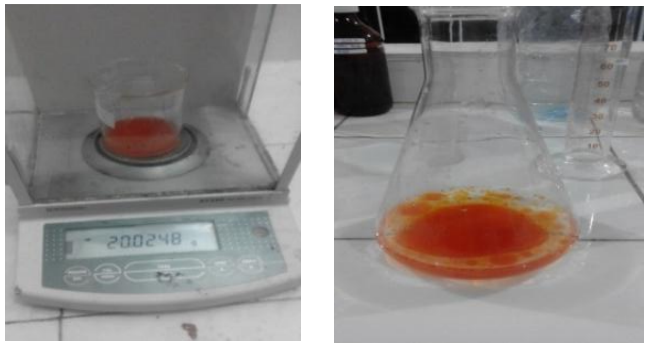

Gambar 2. Proses penimbangan CPO dan penambahan etanol $70 \%$

Setelah dilakuan penambahan etanol ditambahakan $\mathrm{NaOH}$ 0,25M dan BHT 0,3 M seperti pada gambar 3.
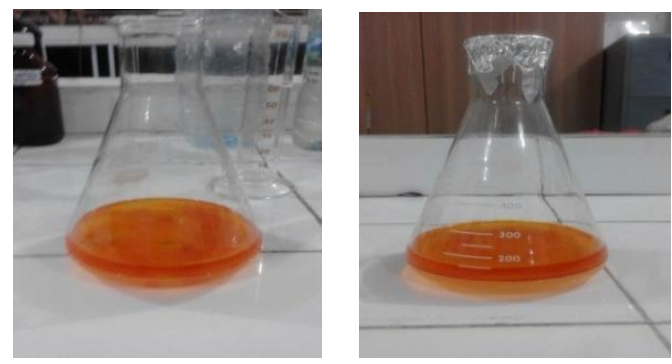

Gambar 3. Penambahan $\mathrm{NaOH}$ dan BHT pada CPO

Selanjutnya dilakukan pemanasan dalam penangas air pada temperatur $70^{\circ} \mathrm{C}$ selama 45 menit dan aduk setiap 5-10 menit dan didinginkan, seperti pada gambar 4.
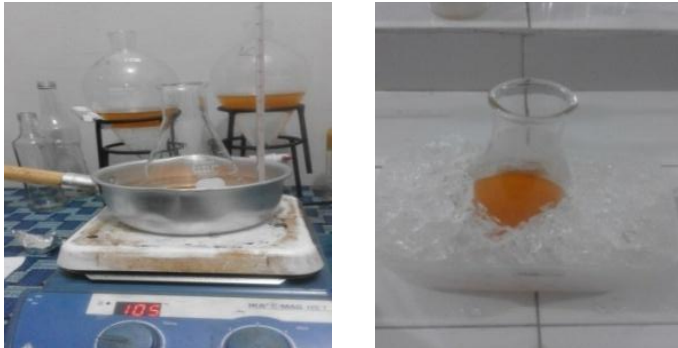

Gambar 4. Proses Saponifikasi pada sampel CPO

Penambahan $\quad \mathrm{NaCl} \quad 0,02 \quad \mathrm{M}$ sebanyak $100 \mathrm{~mL}$ dan dimasukkan kedalam corong pisah tempat reaksi saponifikasi berlangsung dan dibiarkan sampai di dapatkan 3 lapisan, seperti pada gambar 5.
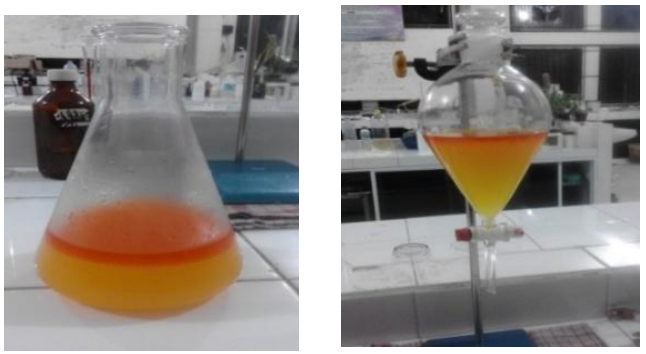

Gambar 5. Reaksi saponifikasi

Hasil reaksi saponifikasi terdiri dari lapisan air (paling bawah), Fraksi fraksi minyak yang tersabunkan (tengah) dan Fraksi minyak yang tak tersabunkan (tengah), seperti pada gambar 6 .

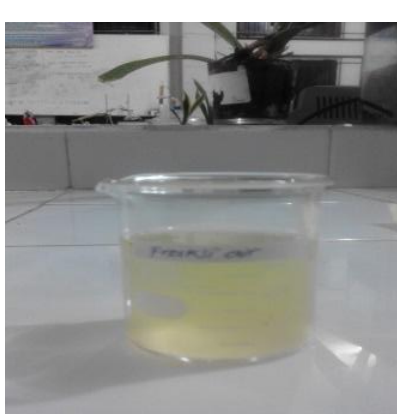

(a)

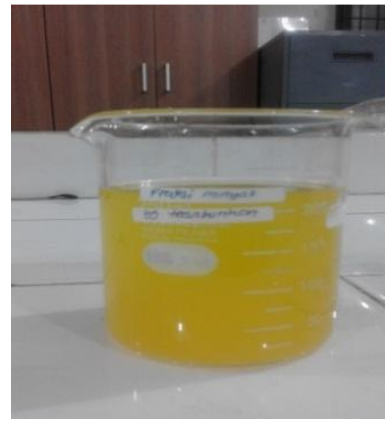

(b)

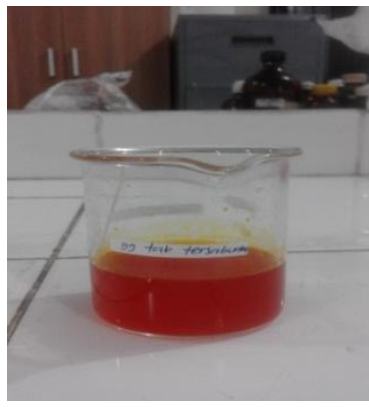

(c)

Gambar 6.Fraksi air (a), fraksi minyak yang tersabunkan (b) dan fraksi minyak atau tak tersabunkan (c) 


\section{Optimasi vitamin E hasil ekstraksi saponifikasi}

Fraksi yang tak tersabunkan ditambahkan $70 \mathrm{~mL}$ Metanol dan didiamkan hingga terbentuk 2 lapisan, seperti pada gambar 7 .

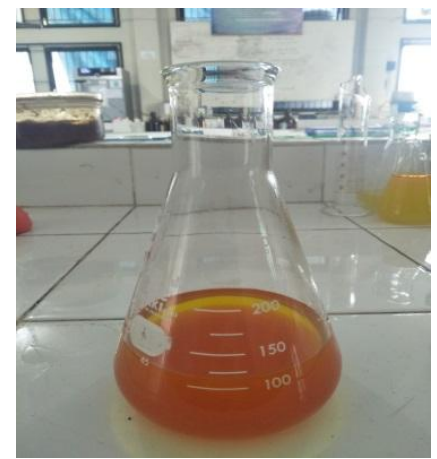

Gambar 7. Fraksi tak tersabunkan dengan penambahan metanol

Terhadap fraksi ini dilakukan isolasi dengan mengambil lapisan atasnya dan ditambahkan 2-propanol (1\%) dalam heksana, seperti pada gambar 8 .

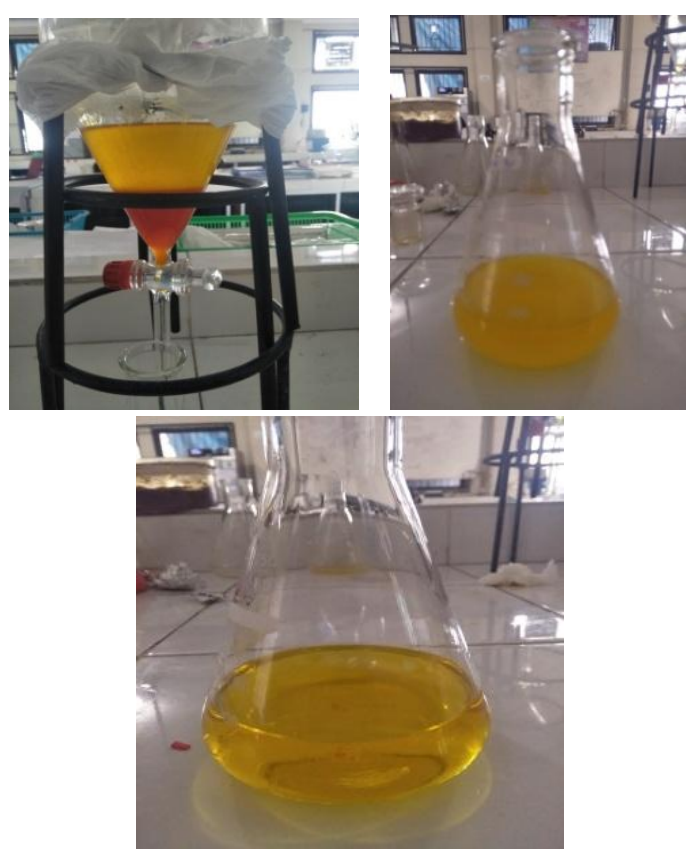

(a) (b) (c)

Gambar 8. Isolasi terhadap vitamin E (a) dipisahkan lapisan atas (b) dan setelah ditambahkan 2-propanol (c)

Sampel (c) ditimbang dan dimasukkan ke dalam vial untuk lebih mempercepat penguapan pelarut, seperti pada gambar 9 .

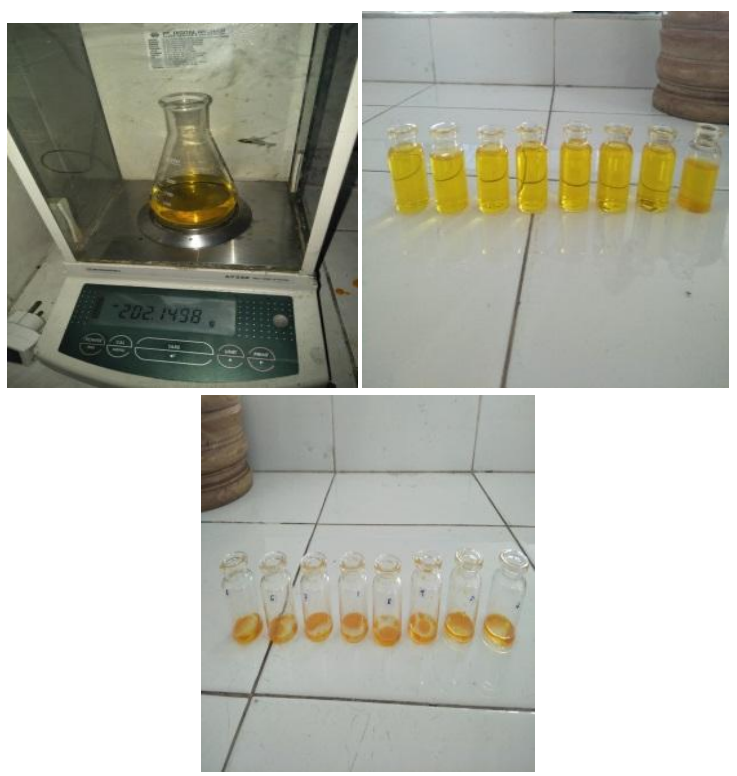

(a)

(b)

(c)

Gambar 9. Vitamin E (a) yang dibiarkan pelarutnya menguap (b) selama satu minggu penguapan (c)

Dari hasil optimasi tokoferol dari CPO didapatkan tokoferol seberat $10,77 \mathrm{gr}$ atau dengan rendemen sebesar 52,77\% (dari 20,71 gr CPO segar). Karakterisasi tokoferol yang diisolasi dilakukan dengan plat KLT dan dielusi dengan pelarut nheksan :etil asetat dan n-heksan : kloroform. Hasil elusi dengan pelarut dilihat dengan lampu UV $254 \mathrm{~nm}$ dan 366 nm. Seperti pada gambar 10

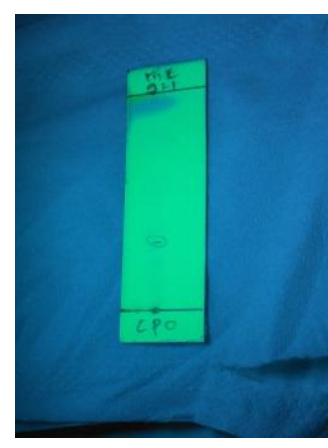

(a)

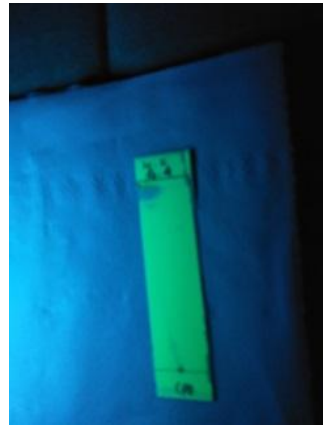

(b) 


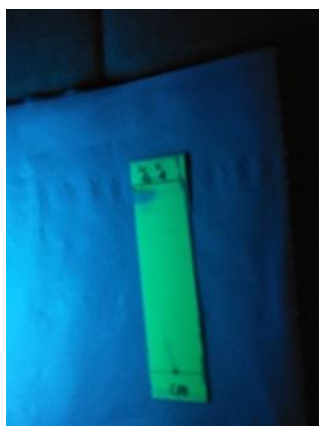

(c)

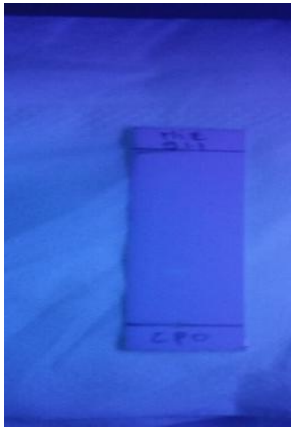

(d)
Gambar 10.Karakterisasi tokoferol pada lampu UV 254 nm(a, b,c) dan 366 nm (d)

\section{KESIMPULAN DAN SARAN}

Dari ekstraksi dan optimasi vitamin E yang dilakukan terhadap CPO didapat disimpulkan antara lain :

1. Sampel CPO segar yang digunakan memenuhi baku mutu CPO segar

2. Rendeman vitamin E yang dihasilkan cukup besar yaitu $52,77 \%$

3. Dari karakterisasi vitamin E yang dihasilkan masih mengandung 2 senyawa

\section{SARAN}

Saran untuk penelitian selanjutnya agar vitamin $\mathrm{E}$ ini sangat mungkin bisa dimurnikan dengan pengoloman, sehingga bisa didapatkan tokoferol murni.

\section{DAFTAR PUSTAKA}

Andula, M. A., Ruslan., Ys Hadi dan Puspitasari, J. D. 2017. Studi perbandingan analisis vitamin $\mathrm{E}$ minyak sawit merah tersaponifikasi antara metode spektrofotometri UVVIS dan KCKT. Kovalen. 3 : 50-57.

Amelia, P, Fithariyah, N., Chairul. 2014. Analisis A-Tokoferol (Vitamin E) Pada minyak biji kelor (Muringa Oleifera Lam.) Secara Kromatografi
Dari hasil karakterisasi dengan KLT dan lampu UV terlihat bahwa vitamin $\mathrm{E}$ yang dihasilkan kemungkinan masih mengandung 2 senyawa, kemungkinan seperti tokoferol dan tokotrienol yang merupakan komponen dari vitamin $\mathrm{E}$

Cair Kinerja Tinggi. Jurnal Kimia Valensi 2 : 142-147.ISSN : 19788193.

Arpi, N. 2014. Kombinasi antioksidan alami $\alpha$-tokoferol dengan asam askorbat dan antioksidan sintesis BHA dengan BHT dalam menghambat ketengikan kelapa gongseng giling ( $U$ Neulheu) selama penyimpanan. Jurnal Teknologi dan Industri Pertanian Indonesia. Universitas Syiah Kuala.

Kresnawaty, I., Budiani, A., Panji, T dan Suharyanto. 2012. Isolasi dan mikroenkapsulasi vitamin $\mathrm{E}$ dari crude palm oil sebagai sumber antioksidan bahan pangan. Menara perkebunan. 2 : 68-76.

Sammugasamy, B., Ramakrishnan, Y., Ghazali, M, H., Muhammad, K. 2013. Combination of saponification and dispersive liquid-liquid microextraction for the determination of tocopherols and tocotrienols in cereals by reservedphase high-performance liquid chromatography. Journal of chromatography A. $1300: 31-37$

Sandhiutami, D. M. N., Ngatidjan dan Kristin, E. 2012. Penetapan kadar tokoferol dalam minyak buah merah (Pandaus conoideus LAM)Dan dalam darah pada tikus wistar jantan yang diberi bahan aktivitas fisik maksimal. Seminar Nasional 
POKJANAS TOI XLII. Universitas Jendral Achmad Yani. Bandung.

Sebayang, F., Kaban, J., Bangun, N., Bulan, R., Putri, N.K., 2016. Enrichment of Tocopherol and Tocotrienol using Polar Adsorbents from Candlenut Oil, Int'1 Journal of Advances in Chemical Engg., \& Biological Sciences (IJACEBS) Vol.
3, (1)ISSN 2349-1507 EISSN 23491515

Sinaga, A.G.S., Siahaan, D. 2015. Characterization and Antioxidant Activity of Non-Polar Extractfrom Crude Palm Oil and Palm Methyl Ester. International Journal of ChemTech Research, Vol.8(4). pp 1810-1816 